\title{
Knowledge, attitude and practices on the care of the newborn in postnatal mothers delivering at a tertiary care centre in Nepal
}

\author{
*Shankar Prasad Yadav1, Mohan Saund², Jitendra Thakur², Punita Yadav³, Sunil Kumar Yadav , Gauri \\ Shankar Shah ${ }^{5}$
}

Sri Lanka Journal of Child Health, 2016; 45(3):189-192

\begin{abstract}
Introduction: Neonatal mortality rate per thousand live births in Nepal is 24.2, and the majority of neonates die during the early neonatal period.
\end{abstract}

Objective: To determine the knowledge, attitudes and practices of mothers regarding care of the newborn after delivery at a tertiary teaching hospital in Nepal.

Method: A cross-sectional study employing both quantitative and qualitative study approaches was conducted in the Maternal and Child Health $(\mathrm{MCH})$ unit of a tertiary hospital in East Nepal for a period of three months. Using a convenient sampling technique 65 postpartum mothers admitted in $\mathrm{MCH}$ unit were enrolled in the study. Structured interview questionnaires were used to collect data. Data was analysed using descriptive statistics by SPSS 20 .

Results: Sixty five mothers who delivered at the tertiary care centre were interviewed. Age of mothers ranged from 16 to 40 years, $63 \%$ were primipara and $18.4 \%$ were illiterate. Whilst $95 \%$ of mothers knew about immunisation, few had acquired knowledge regarding cord care, signs of illness in newborn and newborn feeding during antenatal checkups. Maternal knowledge about newborn danger signs was low. Breast feeding practice as observed by interviewer was not satisfactory. Maternal knowledge on newborn hygiene care was unsatisfactory.

${ }^{1}$ Assistant Professor, Paediatrics and Adolescent
Medicine, ${ }^{2}$ Junior Resident, ${ }^{3}$ Consultant,
${ }^{4}$ Neonatology Resident, ${ }^{5}$ Professor and Head of
Department B.P. Koirala Institute of Health Sciences
Dharan Sunsari, Nepal
*Correspondence: shankardharan@gmail.com
(Received on 7 October 2015: Accepted after
revision on 20 November 2015)

The authors declare that there are no conflicts of interest

Personal funding was used for the project.

Open Access Article published under the Creative

Commons Attribution CC-BY (CC) (P)

Conclusion: Maternal knowledge, attitudes and practices regarding care of the newborn after delivery at the tertiary teaching hospital in Nepal requires improvement.

DOI: http://dx.doi.org/10.4038/sljch.v45i3.8027

(Key words: Knowledge, attitude, practice, mothers, newborn)

\section{Introduction}

Developing countries, like Nepal, face a lot of health challenges as the majority of people are uneducated, poor and less health conscious. As a result, the health status indicators of Nepal still lag far behind those of developed countries. Neonatal mortality rate per thousand live births in Nepal is 24.2 and the majority of neonates die during the early neonatal period ${ }^{1}$. There are numerous unscientific and unhygienic health practices and social taboos in child rearing that makes the newborn extremely vulnerable. This study was conducted in order to determine the contemporary knowledge, attitude and practice of newborn rearing so as to intervene and educate caregivers in future for proper newborn care.

\section{Objective}

To determine knowledge, attitudes and practices of mothers and caregivers regarding care of the newborn after delivery at a tertiary teaching hospital in Nepal.

\section{Method}

A cross-sectional explorative study, employing both quantitative and qualitative study approaches, was conducted in the Maternal and Child Health $(\mathrm{MCH})$ unit of B.P. Koirala Institute of Health Sciences (BPKIHS), a tertiary hospital in eastern Nepal, from December 2014 to February 2015, using a convenient sampling technique. Non-randomly 65 postpartum mothers admitted in the $\mathrm{MCH}$ unit were enrolled in this study. Structured interview questionnaires were used to collect data. Questionnaires along with demographic data included data from the entire targeted domain, i.e. Knowledge, Attitude and Practice of Newborn Care. Approval to conduct the study was taken from the Institutional Ethical Review Board, and participants were briefed about the study in order to gain their informed consent. Data were analyzed using descriptive statistics by SPSS 20 . 


\section{Results}

Sixty five mothers who delivered at BPKIHS were interviewed. Ages of mothers ranged from 16 to 40 years, $44.6 \%$ between 20 to 25 years. Primipara was $63.0 \%$ and $18.4 \%$ were illiterate. Of literate mothers only $29.3 \%$ were job holders. Although $95.3 \%$ of mothers knew about need for antenatal checkups (ANCs), the recommended total of at least four ANCs was achieved only by $63 \%$. Knowledge gained by mothers during ANCs is depicted in Table 1.

Table 1: Knowledge acquired by mothers during antenatal check-ups $(n=65)$

\begin{tabular}{|l|l|}
\hline \multicolumn{1}{|c|}{ Knowledge } & No. (\%) \\
\hline Personal hygiene & $56(86.2)$ \\
\hline Maternal nutrition & $59(90.8)$ \\
\hline Infant nutrition & $10(15.4)$ \\
\hline Cord care & $01(01.5)$ \\
\hline Hospital delivery & $45(69.2)$ \\
\hline Immunization & $62(95.0)$ \\
\hline Breast feeding & $29(44.6)$ \\
\hline Signs of neonatal illness & $05(07.7)$ \\
\hline Family planning & $34(52.3)$ \\
\hline
\end{tabular}

Whilst $95 \%$ of mothers knew about immunisation, only a small percentage of mothers had acquired knowledge regarding cord care, signs of illness in newborn, and newborn feeding during ANCs. Knowledge about newborn danger signs by mothers is shown in Table 2:

Table 2: Maternal knowledge about newborn danger signs $(n=65)$

\begin{tabular}{|l|l|}
\hline \multicolumn{1}{|c|}{ Danger signs } & No. (\%) \\
\hline Lethargy & $29(44.6)$ \\
\hline Abdominal distension & $08(12.3)$ \\
\hline Hyperthermia & $48(73.9)$ \\
\hline Hypothermia & $07(10.8)$ \\
\hline Eye infection & $07(10.8)$ \\
\hline Cord infection & $14(21.5)$ \\
\hline Convulsion & $19(29.2)$ \\
\hline Vomiting & $40(61.5)$ \\
\hline Diarrhoea & $14(21.5)$ \\
\hline Rashes & $08(12.3)$ \\
\hline Jaundice & $45(69.2)$ \\
\hline
\end{tabular}

Due to cultural practice only $64.6 \%$ of mothers wrapped their neonates with new clothes while the remainder used old clothes. Only $61.5 \%$ of mothers breast fed their baby within 30 minutes; $30.7 \%$ of mothers initiated formula feeding at first thinking there was inadequacy of breast secretion and only later switched over to breast feeding. Breast feeding practice as observed by interviewer was not satisfactory (Table 3 ).

Table 3: Appropriate breast feeding practice as observed by interviewer $(n=65)$

\begin{tabular}{|l|c|}
\hline \multicolumn{1}{|c|}{ Feeding Practice } & No. (\%) \\
\hline Comfortable breast feeding position & $58(89.2)$ \\
\hline Supporting neonate & $50(76.9)$ \\
\hline Attachment to breast & $34(52.3)$ \\
\hline Burping post-feeding & $27(41.5)$ \\
\hline
\end{tabular}

Seventy seven percent of mothers fed on demand or at least 8 times a day. Of the 65 mothers, 31 avoided some type of food when a newborn developed jaundice. The percentages of different food items avoided by the mother is demonstrated in Figure 1.

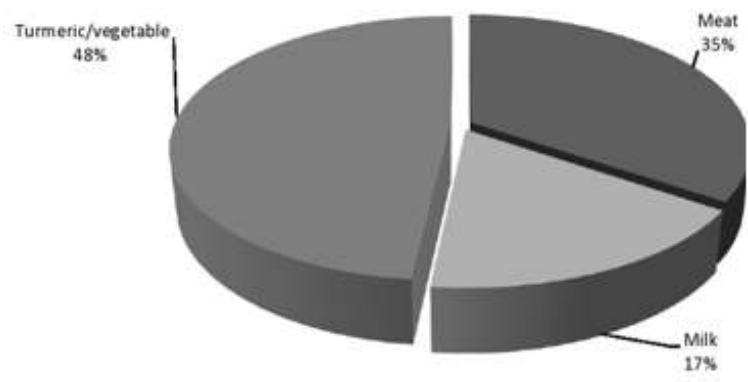

Figure 1: Percentages of food items avoided by mother

Only $52.3 \%$ of mother preferred to exclusively breast feed for 6 months while remaining planned for early weaning. Keeping newborn hygiene clean is one of the cornerstones to prevent newborn illness, the assessment done on mother regarding hygiene practices is demonstrated in Table 4.

Table 4: Maternal knowledge on newborn hygiene

\begin{tabular}{|c|c|}
\hline \\
\hline Hygiene Practice & No. (\%) \\
\hline $\begin{array}{ll}\text { A. } & \text { Hand washing } \\
& \text { Before breast feeding } \\
\text { After diaper care }\end{array}$ & $\begin{array}{l}13(20.0) \\
28(43.1)\end{array}$ \\
\hline $\begin{array}{ll}\text { B. } & \text { Clean the cord with } \\
\text { Warm water and cotton } \\
\text { Oil } \\
\text { Nothing }\end{array}$ & $\begin{array}{l}07(10.8) \\
19(29.2) \\
39(60.0)\end{array}$ \\
\hline $\begin{array}{l}\text { C. Keep new born clean by } \\
\text { Oil massage } \\
\text { Sponge bath } \\
\text { Whole bath } \\
\text { Eye care of newborn }\end{array}$ & $\begin{array}{l}30(46.2) \\
40(61.5) \\
08(12.3) \\
05(07.7)\end{array}$ \\
\hline
\end{tabular}


When newborn becomes sick, $21.5 \%$ preferred traditional methods of healing; $41.5 \%$ exposed newborn to coal or firewood for keeping warm.

\section{Discussion}

It is a well-known fact that the knowledge of newborn rearing, attitude towards newborn care and socio-cultural practice has directly been related to morbidity and mortality of neonates. The major limitation to improve neonatal health status is literacy of care givers, early age at delivery and easy access to health facilities. While $18.4 \%$ of mothers in our study were illiterate, only $63 \%$ recommended antenatal checkups. Better knowledge on neonatal practice was found in older educated women with good socio-economic status and those living in cities $^{2,3}$. Majority of the mothers were unaware of the general danger signs of newborn; over $50 \%$ of the mothers just considered fever, vomiting and jaundice as sign of sickness. Fever and excessive crying was considered to be a general danger sign in a similar study $^{4}$. Majority of care givers in African countries also do not know about signs and symptoms of sepsis, its causes and management ${ }^{5,6}$.

The attitude towards immunization in our study was satisfactory, as about $95 \%$ of mother were concerned about immunizing the child to prevent different communicable diseases. In other studies, a few concerns regarding development of fever post immunization, use of local herbs as a substitute and cultural practice against immunization have been mentioned, but majority of them had a good attitude for vaccination ${ }^{7,8}$. Maintaining good hygiene is an important factor to prevent neonatal infection. We found many cultural practices like wrapping newborn with old clothes, using firewood and coal for keeping baby warm, applying oil to umbilical cord, which can result in neonatal sepsis. Similarly, many mothers did not wash hands after diaper care or knew about eye care. Few other studies also quoted the ignorance of caregivers towards hygienic practices in area of umbilical cord care, thermal care and vaccine preventable disease. There are practices like instillation of oil in nostrils, application of mustard oil over umbilicus, and poor hand washing practices $^{9,10}$.

In our study we found major lagging in proper breast feeding technique like supporting neonate $(77 \%)$, attachment to the breast $(52 \%)$ and burping after feeding $(41.5 \%)$. Approximately $60 \%$ of mother initiated breast feeding within thirty minutes and about $20 \%$ of mother did not give adequate feeding. There is cultural practice of abstinence of different food items during neonatal jaundice, which in turn may decrease the calorie intake of mother and affect milk production. About half of mother has planned for exclusive breast feeding for six months. This can have direct impact on risk of diarrhoeal and respiratory illness. A quarter of them believe in cultural ways of treating jaundice and illness and result is often they present very late at health care, increasing avoidable neonatal mortality and morbidity. Similar studies found that knowledge of exclusive breast feeding was present in about $35-40 \%$ and knowledge regarding techniques like proper position of the baby and burping practices was found in $35 \%$ and $78.2 \%$ respectively ${ }^{11,12}$. Community based study conducted in Sudan indicated that $54.2 \%$ of mothers initiated breastfeeding after one hour from delivery and $39.7 \%$ of them initiated breastfeeding during from two hours to 24 hours ${ }^{13}$. Another study from Iran found that $14 \%$ mothers go for traditional remedies and $32 \%$ mothers discontinued feeding their icteric offspring with coloured foods and colostrum ${ }^{14}$.

In our study we found that practice of mothers in newborn are still lagging in some aspects like recognizing sick newborn, managing jaundice, feeding practices and hygiene care. All this practices have direct impact on neonatal health status. These lacunae are because of deep rooted cultural and traditional beliefs among care givers and ignorance. Hence to overcome this problem increasing overall educational status of mothers, providing proper health education to them regarding care of newborn, running baby friendly clinics and discouraging the unhealthy traditional beliefs are very important.

\section{Conclusion}

Maternal knowledge, attitudes and practices regarding care of the newborn after delivery at the tertiary teaching hospital in Nepal is unsatisfactory

\section{References}

1. UNICEF/WHO/ World Bank/UN. Levels and Trends in Child Mortality. Report 2013. Available from: http://www.childinfo.org/files/Child_Mortali ty_Report_2013.pdf

2. Padiyath $\mathrm{M}$, Bhat $\mathrm{V}$, Ekambaram $\mathrm{M}$. Knowledge, attitude and practices of neonatal care among postnatal mothers. Current Pediatric Research 2010; 14(2): 147-52. 
3. Helmy F, Bahgat S. Newborn care giving by primipara and multipara mothers at home in Tanta City. Journal of the Egyptian Public Health Association 1998; 73(5-6):501-18. PMid: 17217021

4. Awasthi S, Verma T, Agarwal M. Danger signs of neonatal illnesses perception of care givers and health workers amongst mothers in India. Bull World Health Organization 2006; 84(10):819-26. http://dx.doi.org/10.2471/BLT.05.029207

5. Chibwana AI, Mathanga DP, Chinkhumba J, Campbell CH. Social cultural predictors of health seeking behaviour for febrile under five children in Mwanza Neno district, Malawi. Malaria Journal 2009; 8:219. http://dx.doi.org/10.1186/1475-2875-8-219 PMid: 19778433 PMCid: PMC2763003

6. Tarimo D, Lwihula G, Minjas J, Bygbjerg C. Mothers' perceptions and knowledge on childhood malaria in the holoendemic Kibaha district, Tanzania: implications for malaria control and the IMCI strategy. Tropical Medicine and International Health. 2000; 5:179-84.

http://dx.doi.org/10.1046/j.13653156.2000.0 0537.x

PMid: 10747280

7. Adeyinka D, Oladimeji O, Adeyinka F, Aimakhu C. Uptake of childhood immunization among mothers of under-five in southwestern Nigeria. The Internet Journal of Epidemiology 2008; 7:2. Available from: http://ispub.com/IJE/7/2/3255

8. Cyprian O. Knowledge, attitudes and practices of caretakers of malnourished children in Aweil East and North counties, South Sudan 2011. Available from: http://www.southsudanmedicaljournal.com/a rchive/february-2011/ knowledge-attitudesand-practises-of-caretakers-ofmalnourishedchildren-in-aweil-east-and-north-countiessouth-sudan.html
9. Kaur A, Chowudry S, Kumar R. Mothers beliefs and practices regarding prevention and management of diarrhoeal diseases. Indian Pediatrics 1994; 1:55-7.

10. Aghamohammadi A, Zafari M, Moslemi L. Comparing the effect of topical application of human milk and dry cord care on umbilical cord separation time in healthy newborn infants. Iranian Journal of Pediatrics 2012; 22(2): 158-62.

http://dx.doi.org/10.1046/j.13653156.2000.0 0537.x

PMid: 10747280

11. Ekambaram M, Bhat B V, Ahamed Mohd AP. Knowledge, attitiude and practice of breastfeeding among postnatal mothers. Current Pediatric Research 2010; 14(2): 119-24

12. Mital P, Hooja N, Bansal A, Salvi A, Andaleeb F, Makkar P. Knowledge, Attitude and Practice of Breast Feeding at a Tertiary Care Centre in Rajasthan. Scholars Academic Journal of Biosciences 2014; 2(10): 714-18.

13. Haroun H, Mahfouz M, Ibrahim B. Breast feeding indicators in Sudan: A case study of Wad Medani town. Sudanese Journal of Public Health 2008; 3(2): 81-90.

14. Amirshaghaghi A, Ghabili K, M.Shoja M, Kooshavar H. Neonatal Jaundice: Knowledge and Practice of Iranian Mothers with Icteric Newborns. Pakistan Journal of Biological Sciences 2008; 11(6): 942-5. 